\title{
Liver cavernosal hemanginoma in childhood: a case report
}

Aloysio Ikaro Martins Coelho Costa 1, Érica Paulinne Pereira Brandão 2, Fernando Fernandes Rodrigues 2, *, Lorrana Xavier do Nascimento 3, Natalia Verzeletti Oliveira 1, Tiago Magalhães Cardoso 1

${ }^{1}$ General Surgery Service, Fundação Hospital Adriano Jorge, Amazônia, AM, Brazil.

${ }^{2}$ Department of Medicine, Fametro University Center, Amazônia, AM, Brazil.

${ }^{3}$ Department of Medicine, State University of Amazonas, Amazônia, AM, Brazil.

*Corresponding author: Fernando Fernandes Rodrigues. Parque dos Franceses, nº96-Dom Pedro. Zip Code: 69050-045-Amazonas, AM, Brazil. Phone: +55(93) 99191-6241. E-mail: fernandesfernando292@yahoo.com.

Research Ethics Committee Approval (if necessary): We declare that the patient approved the study by signing an informed consent form and the study followed the ethical guidelines established by the Declaration of Helsinki.

Received on: Sep 30, 2021. Accepted on: Oct 19, 2021. Available online: Oct 26, 2021.

\begin{abstract}
Cavernous hemangiomas are benign tumors that present a low risk of bleeding when considering their high prevalence. They are frequent in the liver, with a frequency of 5 to $20 \%$ in the population. They present an increased risk of rupture when larger than $10 \mathrm{~cm}$ and with central necrosis. It is a most common primary liver lesion, and its diagnosis can be made incidentally during nonspecific evaluation of abdominal complaints. It can be diagnosed in all age groups, most frequently in women around $30-50$ years of age, and rarely in children over three years of age. About $90 \%$ of these lesions are diagnosed in the first six months of life.
\end{abstract}

Keywords: Cavernous Hemangioma; Liver Damage; Child.

\section{Introduction}

Cavernous hemangioma $(\mathrm{CH})$ is the most common benign primary tumor, with the liver being the most affected internal organ. Most of these tumors are less than $5 \mathrm{~cm}$ in diameter. When it reaches more than $4 \mathrm{~cm}$ in diameter, they are called giant hepatic hemangiomas (HHG) and correspond to $10 \%$ of all cases. These tumors form a non-epithelial lesion of vascular origin of unknown etiology, however, there is evidence of a relationship with female hormones. Multiples are multiples, peripherals and various sizes. 
The main symptom of this injury is abdominal pain, which is the main indication for surgical treatment. The prevalence of hemangiomas is estimated to be around $5 \%$ on imaging tests, but they are evidenced in more than $20 \%$ on autopsies. It can be diagnosed in all age groups, most often in women around 30-50 years old, and it is rare in children.

The present report is about a female child diagnosed with capillary and cavernous hemangioma of the liver, submitted to resection of hepatic hemangioma and sub segmentectomy IV, V, VI and cholecystectomy.

\section{Case report}

On physical examination, the patient had more evident semiglobular abdomen in the right hypochondrium, without collateral circulation, slightly painful on palpation and with the presence of air-fluid noise. A palpable liver was identified about $8 \mathrm{~cm}$ below the costal margin, without pain on decompression. The patient's mother denies comorbidities, allergies, previous transfusions, and no history of neoplastic or liver disease.

An angiographic examination was performed, which showed hepatic hemangioma irrigated by branches of the right and left hepatic arteries and irrigation by branches of the portal vein.
Computed tomography (CT) of the abdomen was also performed (Figure 1), which showed a heterogeneous lobulated lesion with venous contrast enhancement in close contact with segments IV, V and VI of the liver, pancreas head and retroperitoneum extending up to the right iliac fossa, determining compression and displacement of adjacent structures with about $16 \times 9.3 \times 9.4 \mathrm{~cm}$ and volume of $727.3 \mathrm{~cm}^{3}$ (Figure 1). Doppler ultrasonography (US) showed a solid lesion in the right lobe (segment V) of the anterior hepatic region, with the presence of biphasic circulatory flow (image not presented).

An attempt at surgical resection was performed, however, the outcome of this attempt was only removal of the specimen for biopsy, which was performed outside the unit, and later, the patient was referred to our service for evaluation. The histopathological result of the surgical specimen (Figure 2) confirmed hepatic cavernous hemangioma. 


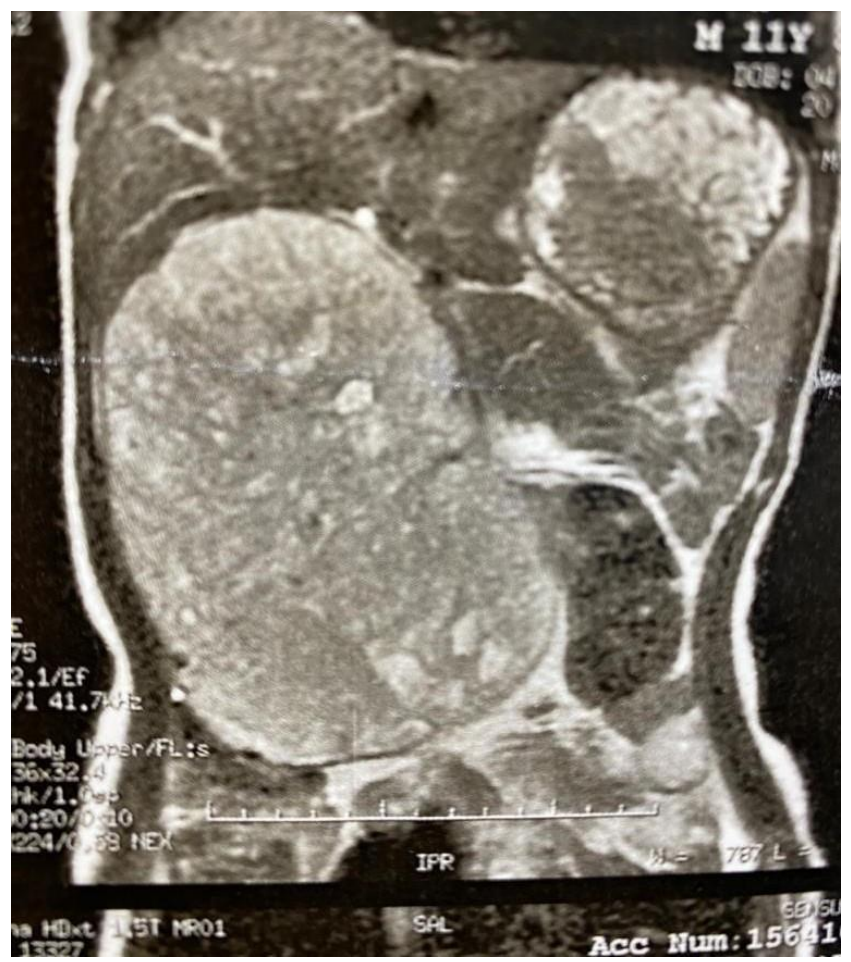

Figure 1. Abdominal CT scan showing a lobulated lesion, with great extension to the right iliac fossa. Compression and displacement of adjacent structures measuring about $16 \times 9.3 \times 9.4 \mathrm{~cm}$.

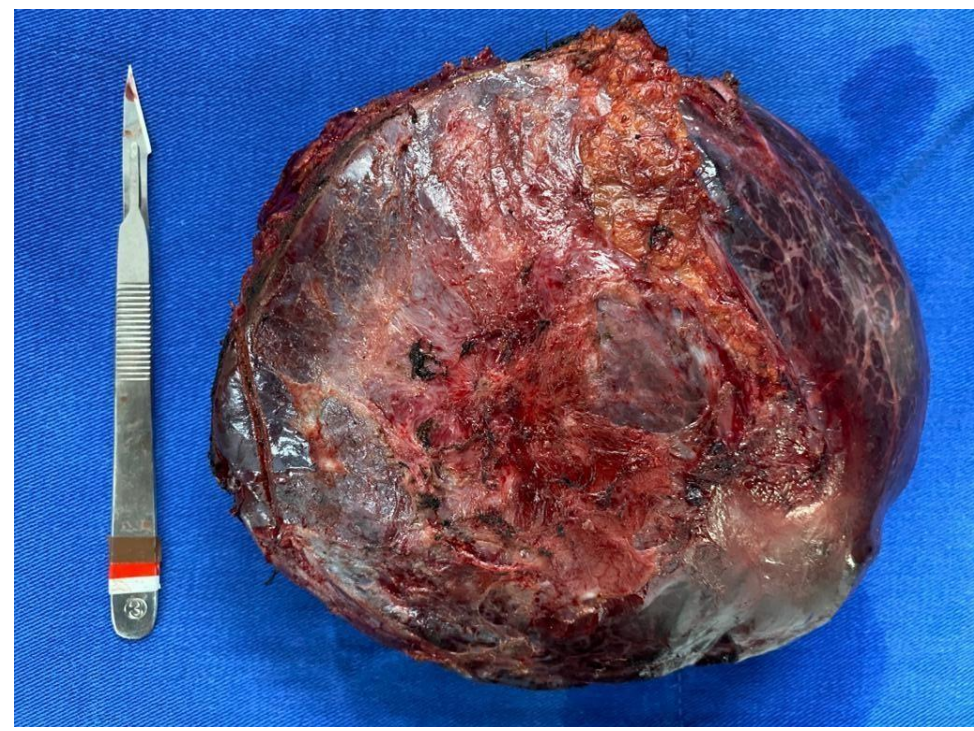

Figure 2. Surgical piece removed.

After about a year of of hepatic hemangioma and IV, V, VI investigation, she underwent resection and cholecystectomy sub 
segmentectomy, where a liver lesion measuring about $15 \mathrm{~cm}$, exophilic, without involvement of the hepatic hilum was evidenced (Figure 3).

The postoperative period was followed in the Intensive Care Unit (ICU) bed, where a good clinical evolution was noted, without the need for blood transfusion or vasoactive drugs, progressing with the diet and carrying out prophylactic antibiotic therapy without complications. She was discharged from the ICU to the ward on the (3rd) postoperative day. Blake's drain with decreasing output was in good aspect, being removed uneventfully. She was discharged from the hospital on the 7 th postoperative day, being released with a prescription for symptomatic patients, use of an abdominal girdle and high-compression elastic stockings. The patient evolved with satisfactory postoperative recovery, with no complaints and complete remission of symptoms.

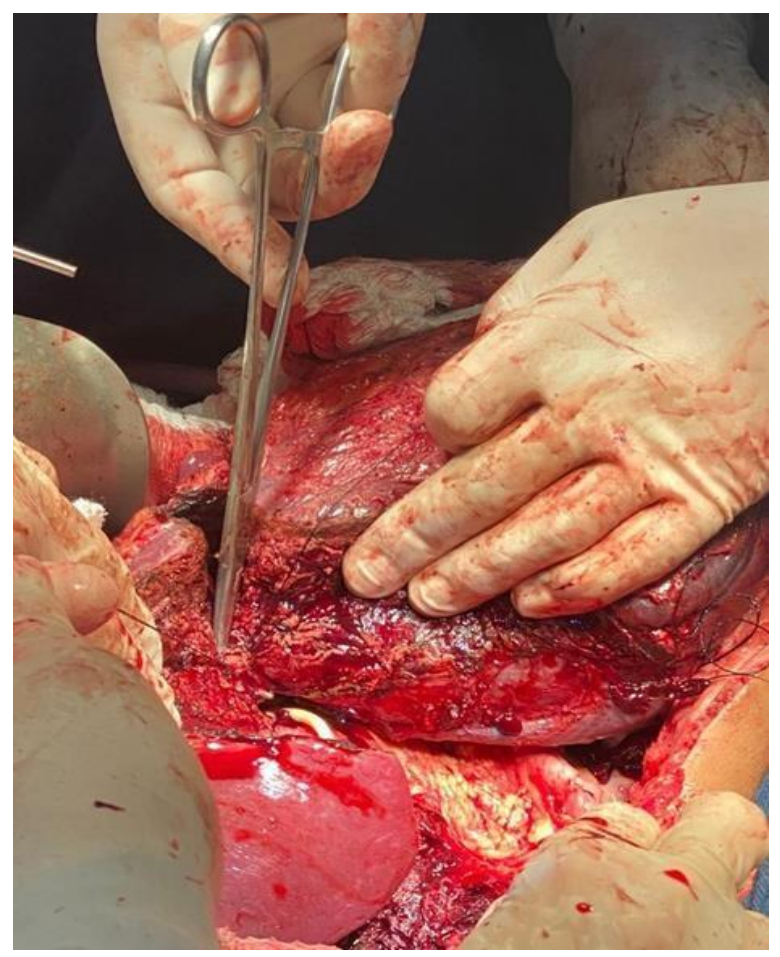

Figure 3. Resection of hepatic hemangioma and sub segmentectomy IV, V, VI and cholecystectomy, where the liver lesion measuring about $15 \mathrm{~cm}$ was evidenced.

\section{Discussion and Conclusion}

In 1898, the first hemangioma treated with liver resection by Hermann
Pfannestil was reported. More than a hundred years later, tumor enucleation was described in the literature. Enucleation with inflow control is one of 
the ways of resection of hemangiomas and has shown a lower rate of complications when compared to hepatectomies.

Hepatic hemangiomas represent about $12 \%$ of infantile liver tumors. Large hemangiomas in children can result in congestive heart failure secondary to arteriovenous shunt. Laparoscopic liver surgery may be eligible in patients with peripheral benign lesions, such as those located in segments II and III or segments V and VI. Large lesions in the right lobe or more centrally located with involvement of the portal vein, inferior vena cava, or proximal hilar are best approached through the open approach.

Hepatic hemangiomas are common benign lesions, typically identified on imaging tests indicated for other reasons. However, depending on the type of injury or injuries found, symptoms may develop, the main ones being abdominal pain, compression of adjacent structures and hematological complications. Still, most injuries are treated conservatively, with outpatient follow-up and periodic imaging exams.

Surgical indication should not only consider isolated aspects of the lesion, but it is observed that laparoscopic enucleation can bring similar results to open surgery, with less risk of bleeding and shorter hospital stay. Despite this, in patients with voluminous lesions, from more central locations, open surgery seems to be better indicated. In any case, for all cases, all treatment options available for this benign lesion, which in most cases is asymptomatic and commonly unknown by its patients, must be evaluated.

\section{References}

[1] European Association for the Study of the Liver (EASL). EASL Clinical Practice Guidelines on the management of benign liver tumours. J Hepatol. 2016 Aug;65(2):386-98.

doi: 10.1016/j.jhep.2016.04.001.

[2] Giulianotti PC, Bustos R, Valle V, Aguiluz G, Pavelko Y, Fernandes E. Robot-assisted enucleation of gigantic liver hemangiomas: Case series of 3 patients. Int J Surg Case Rep. 2019;60:244-248. doi: 10.1016/j.jijscr.2019.06.033.

[3] Ketchum WA, Lin-Hurtubise KM, Ochmanek E, Ishihara K, Rice RD. Management of Symptomatic Hepatic "Mega" Hemangioma. Hawaii J Med Public Health. 2019 Apr;78(4):128-131.

[4] Leon M, Chavez L, Surani S. Hepatic hemangioma: What internists need to know. World J Gastroenterol. 2020 Jan 7;26(1):11-20. doi: 10.3748/wjg.v26.i1.11.

[5] Liu Y, Wei X, Wang K, Shan Q, Dai $\mathrm{H}$, Xie $\mathrm{H}$, Zhou L, Xu X, Zheng $\mathrm{S}$. 
Enucleation versus Anatomic Resection for Giant Hepatic Hemangioma: A Meta-Analysis. Gastrointest Tumors. 2017 Mar;3(3-4):153-162. doi: $10.1159 / 000455846$.

[6] Miura JT, Amini A, Schmocker R, Nichols S, Sukato D, Winslow ER, Spolverato G, Ejaz A, Squires $\mathrm{MH}$, Kooby DA, Maithel SK, Li A, Wu MC, Sarmiento JM, Bloomston M, Christians KK, Johnston FM, Tsai S, Turaga KK, Tsung A, Pawlik TM, Gamblin TC. Surgical management of hepatic hemangiomas: a multi-institutional experience. HPB (Oxford). 2014 Oct;16(10):924-8. doi: 10.1111/hpb.12291.

[7] Mogahed MM, Zytoon AA, Essa B, Abdellatif W, Ghanem N, ElWakkel B. Natural history of hepatic hemangiomas as a guide for surgical indication. Egypt Liver Journal. 2020;10:56. https://doi.org/10.1186/s43066-02000065-5.

[8] Toro A, Mahfouz AE, Ardiri A, Malaguarnera $M$, Malaguarnera $G$, Loria F, Bertino G, Di Carlo I. What is changing in indications and treatment of hepatic hemangiomas. A review. Ann Hepatol. 2014 Jul-Aug;13(4):327-39.

Conflict of interest: The author declares no conflicts of interest.

Acknowledgements: None.

Funding: None.
How to cite this article: Costa AIMC, Brandão EPP, Rodrigues FF, Nascimento LX, Oliveira NV, Cardoso TM. Liver cavernosal hemanginoma in childhood: a case report. Brazilian Journal of Case Reports. 2021 OctDec;01(4):84-89. 